\title{
Research on Financing Difficulties of China's Small and Medium-sized Enterprises
}

\author{
Sihan Feng \\ Shanghai hongrunboyuan School, Shanghai 200003, China \\ Suibian886@126.com
}

\begin{abstract}
SMES are an important part of China's market economy. SMES can not only increase employment and stabilize prices, but also play an important role in promoting economic growth and maintaining balance of payments. At present, China's SMES are faced with few financing channels, high financing cost, poor continuous capital inflow, difficult to obtain long-term loans, low credit rating problems. By analyzing the causes of these problems, the government and enterprises formulate optimized policies, which is helpful to solve the financing problems of small and Medium-sized enterprises.
\end{abstract}

Keywords: SME Financing; Corporate Finance.

\section{Introduction}

SMES are an important pillar of China's economic development and have made contributions to China's economic construction. However, due to financing difficulties and their own reasons, the development of SMES is hindered, which has a negative impact on China's economic development. Using literature analysis method. First, this paper introduces the definition and characteristics of SMES. Secondly, this paper analyzes the financing status of SMES, and expounds the financing difficulties of SMES. Then, this paper explores the reasons for the financing difficulties of SMES. Finally makes a summary of this research. It is expected that through this analysis, the financing problems of SMES can be solved, to promote the healthy development of SMES.

\section{Definition of SMES}

SMES are characterized by small scale, flexible operation, imperfect system and poor risk control ability. Medium-sized enterprises refer to enterprises with operating income of more than 5 million yuan, and small enterprises refer to enterprises with operating income of more than 500,000 yuan. [1]

\section{Financing Status of SMES}

In recent years, with the deepening of reform, the financing channels of China's SMES are more diversified, including equity financing and bond financing. Equity financing includes angel investment, independent investment, listed investment, stock issuance, financial investment, etc. Bond financing includes secured loans, private loans, trade loans, financial company loans, bond issuance, pawn loans, etc. [2]. Although financing channels become more diversified, but due to the imperfect guarantee mechanism, poor quality of collateral, information exchange is not timely, SMES loan interest rate is high, resulting in many SMES loan needs have not been met.

\subsection{Financing Mode of SMES}

With the support of Internet technology, the financing mode of SMES is also changing, mainly divided into the following three types. The first is crowdfunding, which means collecting funds from netizens in the form of group buying. Crowdfunding makes use of the communication of the Internet, so that entrepreneurs and individuals can comprehensively show their projects to the public and gain public support, thus obtaining financial assistance. The second type of financing is $\mathrm{P} 2 \mathrm{P}$, which is a type of Internet finance. P2P refers to person-to-person small-amount lending, which usually requires 
the use of business network platforms to establish relationships between lenders and borrowers and complete transaction procedures. Borrowers can release the loan amount, time, interest, repayment method, relatively free. The third financing method is e-commerce finance, which means that thirdparty e-commerce enterprises provide funds to SMES through financing platforms. [3]

\subsection{Financing Difficulties of SMES}

\subsubsection{Few Financing Channels}

Nowadays, although there are many SMES in China. Their overall operation scale is small, so they lack economic strength. Therefore, we can only borrow money through banks, but banks are strict about their loan qualification, and the amount that can be borrowed is small, which is difficult to meet the loan needs. Since SMES lack collateral when they borrow money, banks can reject their loan applications. Therefore, it is difficult for SMES to obtain broad financing channels. If the economic environment is not good, they may go bankrupt due to lack of sufficient funds.

\subsubsection{High Financing Costs}

In the process of loans, SMES not only have to pay interest, but also must pay insurance and management fees, and there is no interest rate preference, so they need high financing costs. Because the bank usually uses the loan of SMES to assure or pledge means, the procedure is not only complex, trivial, and the enterprise should pay asset appraisal fee, guarantee insurance fee, labor service fee and so on. When SMES face financial emergencies, they have no choice but to seek private capital. Although the approval time of loans is fast, they must pay higher interest, which undoubtedly increases the economic burden of SMES.

\subsubsection{It is Difficult for SMES to Obtain Long-term Loans Due to the Small Amount of Financing}

Among all kinds of financing problems faced by SMES, the problem of small amount of financing and difficult to obtain long-term loans generally occurs, which leads to the shortage of working capital. Banks generally believe that there are many uncertain factors in the cash flow of SMES. Banks are willing to provide additional funds to supplement the cash flow of SMES when the cash flow is relatively comfortable, but they may withdraw the loan line when the cash flow of middle and lower enterprises is tight. In order to obtain funds, enterprises will adopt a variety of ways, some lending companies set more stringent conditions, the approved amount of capital is low, and the loan term is only one year, after the expiration of SMES to re-evaluate the ability to repay.

\section{Analysis of Reasons for Financing Difficulties of SMES}

\subsection{Analysis of Internal Causes of Financing Difficulties of SMES}

\subsubsection{SMES are Small in Scale and Lack of Competitive Strength}

There are a large number of enterprises in China's market, among which SMES account for more than $70 \%$ of the total number of Enterprises in China, but their contribution to the total economic output value is only about $40 \%$ [4]. That is to say, although there are many SMES in China, it is difficult to form a scale, and there are few SMES with core technologies in the industry. As a result, SMES in China have no right to speak in the industry and the market, no obvious development advantages, small financing volume and poor financing effect.

\subsubsection{High Operational Risk, Low Risk Resistance Ability and Lack of Good Credit}

Large operational risks and poor market risk resistance are common problems of SMES in China [5]. China's SMES generally lack efficient and advanced management system and risk resistance system, so the internal mechanism construction of the company is not perfect, and the credit consciousness of enterprise leaders is not strong, lack of good credit management. Because some SMES have published untrue information, seriously reduce the trust of financial institutions to SMES. 
In China's economically backward areas, some SMES have weak credit awareness, often refuse to repay loans on the grounds of poor operating status, or even use various methods to apply loans, and refuse to repay loans after reaching the loan term, thus lowering their credit rating. It is difficult for investors to see the basic information of enterprises and make accurate judgment on their financing, so it is difficult to obtain the trust of financing institutions.

\subsection{Analysis of External Causes of Financing Difficulties of SMES}

\subsubsection{SMES Lack Government Support Policies}

Although China's current economic development trend is good, the economic volume is getting bigger and bigger, but the lack of government support policies for SMES. It is mainly reflected in two aspects. The first aspect is that the amount of government support policies for SMES is small. For example, common ways such as store rent reduction and tax reduction play a limited role in the development of SMES. This shows that tax breaks and other policies are not entirely suitable for SMES. Policy support measures for SMES need to be more targeted and diversified, and targeted government support policies need to be formulated for SMES in different industries and in different forms. The second aspect is the lack of subjective initiative of the government on SMES. Both the central and local governments attach great importance to the results of market economy and attach great importance to the prosperity and diversity of market economy. However, due to the large number and small scale of SMES, the financing intention and intensity of local governments towards SMES and large enterprises are obviously biased [6].

\subsubsection{Imperfect Mechanism of Financial Institutions}

SMES need to rely on financial institutions for financing. A region with perfect financial institutions and diversified financing methods for SMES will have a good financing result. China's overall financial and financing environment is not perfect, with obvious financing bias. For large enterprises and state-owned enterprises, there is an obvious favorable financing orientation, while for SMES, the financing environment is not good. This situation is reflected in the financing difficulties, small financing amount, narrow financing channels and low financing competitiveness of SMES in China [7]. The fundamental reason for the imperfect financing institutions and mechanisms of SMES in China is that the mechanism of financial institutions in China develops late, and relevant policies and systems are still being improved. China's financial institutions tend to be conservative, and many SMES have low ability to resist market risks, which leads to China's financial institutions preferring to choose traditional enterprises for investment. Second, according to the rate of return on investment, China's large enterprises and state-owned enterprises have a higher rate of return on investment, while SMES have a lower rate of return on investment, which may even cause serious investment risks [8]. Therefore, China's financial institutions actively and actively lend money to large enterprises and state-owned enterprises, while maintaining a lofty attitude when SMES need financing, resulting in financing difficulties for China's SMES and the abnormal development of China's financing market.

\section{Study on Countermeasures to Solve Financing Difficulties of SMES}

\subsection{Study on Countermeasures to Solve Financing Difficulties Within the Enterprise}

In the operation of SMES, financing results are not only restricted by their own theoretical knowledge, but also affected by internal and external environment [9]. Therefore, we should not only strengthen the internal management of enterprises, but also gradually improve the internal economic environment of enterprises. Leaders of SMES should strive to improve the internal economic environment and operation status of enterprises, strengthen the practical application of financing, finance and other related positions in business decision-making, establish the internal financing management system of enterprises, and recruit and train relevant talents. Enhance the awareness of corporate leadership on financing management. For the staff in the financing management department, regular training should be done, the training content should be enriched, and a perfect training 
mechanism should be established. Encourage senior financial managers of enterprises to actively obtain the CMA qualification, and regularly teach accounting and financing personnel what they have learned, so that accounting practitioners can master more theoretical knowledge of financing management.

\subsection{Study on the Government's Countermeasures to Solve the Financing Difficulties of SMES}

At the government level, the central government and local governments should strengthen support for SMES, and the central government should formulate supportive policies favorable to SMES [10]. Local governments should take the support policies for SMES formulated by the central government as the core and benchmark, and formulate targeted support and preferential policies for SMES according to the actual conditions of their respective regions. Support and preferential policies for SMES should be extensive, universal and contemporary, not just based on past experience. To the region to carry out the actual situation of market economy, SMES of real demand, the actual situation of local financial markets and market research, developed the policy not only has the universality, proactive, able to meet the present and future to the greatest extent under a certain time period, the actual benefit of SMES and the actual demand. Constantly improve the legal system, do a good job in the corresponding laws and regulations of enterprise financing, so that the enterprise financing process can have laws to follow, so that the enterprise financing behavior becomes more standardized, to enhance the competitiveness of enterprises.

\section{Summary}

Nowadays, China's SMES economic foundation is relatively weak, in the process of financing, often at a disadvantage. As can be seen from the above research, banks are stricter in the approval of SMES, which is not conducive to the development of SMES because the loan amount is small and the approval time is long. Therefore, the society should strengthen the importance of SMES financing, the government should change its functions, through the establishment of SMES development bank, to provide professional financial services, to solve their financing difficulties.

\section{References}

[1] Chen Jiatao. Research on the causes and Countermeasures of Financing difficulties of China's SMES. Economic Research Guide, 201,11(05):219-221.

[2] Wang Ying. Research on financing problems and Countermeasures of SMES in Xi 'an city. China Business Theory, 2019 (9):2.

[3] Yuan Zhigang, Guo Xueqi, Ge Jinfeng. Financing of SMES and the development of Small and Mediumsized banks --Theoretical and Empirical Analysis triggered by China's Practical Problems. Shanghai Economic Research, 201,14(08):117-118.

[4] Pang Yanhong. Analysis of financing difficulties of SMES in China. Accounting for Township Enterprises in China, 201,16(9):241-242.

[5] Gao Min. The Problem of financing difficulty and Expensive financing for SMES. China's SMES, 2020,301(12):173-174.

[6] Zhu Xutong. Analysis on financing difficulties of SMES. Finance information, 2019,13(21):176-177.

[7] Zhao jianhui. Research on financing problems of SMES in China. Commercial accounting, 2019, 15 (8): 420-422.

[8] Wei Chong. Research on financing problems of SMES in rural Areas -- Taking Dehui City of Jilin Province as an example. Jilin financial research, 2019,24(7)215-216.

[9] Qu Fanchang. Research and countermeasures on financing guarantee of SMES in China. Consumer guide, 2019, 14(035):166-167.

[10] Wang Xinyang, WANG Jingyi. Research on financing problems of SMES in China under the new situation. Foreign economic and trade, 2019,13(9):312-313. 